\title{
Uma Língua Inglesa para chamar de minha: equivocações sobre o bom falante de inglês
}

\author{
Helena Regina Esteves de Camargo \\ Universidade Estadual de Campinas (UNICAMP), Campinas, São Paulo, Brasil \\ helcamargo@yahoo.com.br
}

DOI: http://dx.doi.org/10.21165/el.v45i2.597

\begin{abstract}
Resumo
O objetivo deste artigo é problematizar a tradição de ensino e aprendizado de inglês que observa qualquer desvio dos padrões do "falante nativo" como sinais de deficiência. Para tanto, proponho uma revisão teórica sobre a relação entre língua e cultura e sobre práticas discursivas de falantes bilíngues. Após analisar excertos extraídos de observações de aulas de inglês para adolescentes brasileiros em aulas particulares e em uma escola bilíngue, concluo que há duas representações equivocadas acerca do processo de ensino e aprendizado de inglês: (i) misturar as línguas é sinal de incompetência e (ii) marcas locais de uso do inglês sinalizam falhas no processo de ensino e aprendizado da língua.
\end{abstract}

Palavras-chave: política linguística; educação bilíngue; língua inglesa.

English Language of My Own: Misconceptions about the Good English Language Speaker

\begin{abstract}
The objective of this paper is to problematize the English teaching and learning tradition that understands any deviation from "native speakers"" standards as a sign of deficiency. For this reason, the theory on the relationship between language and culture and on bilinguals' discursive practices is reviewed. After analyzing excerpts taken from observations of English classes for Brazilian teenagers both in private lessons and in a bilingual school, it is concluded that there are two misleading representations of the process of teaching and learning English: (i) mixing languages is a sign of incompetence, and (ii) local marks in the use of English indicates flaws in the process of teaching and learning this language.
\end{abstract}

Keywords: Language Policy; bilingual education; English language.

\section{Introdução}

Muito comumente, ouvimos dizer que não saber inglês nos dias de hoje equivale a ser analfabeto. Isso porque, de fato, a Língua Inglesa está consolidada, atualmente, como a língua dos negócios, da tecnologia, da cultura e da ciência no mundo inteiro. Quando pensamos nas divulgações científicas, no cinema, na música e no mercado financeiro, por exemplo, percebemos que a maior parte da comunicação em escala mundial é feita em inglês. Claro que o poder conferido à língua inglesa não é aleatório, pois está atrelado ao poder político, militar, tecnológico, econômico e cultural de países anglófonos hegemônicos, principalmente a Grã-Bretanha e os Estados Unidos, que levam o inglês pelo mundo desde o século XVI (LACOSTE, 2005). O prestígio desses 
países, nota-se, estende-se não somente à língua inglesa, mas às variantes do inglês neles utilizadas.

Percebe-se, portanto, que a disseminação do inglês, conforme aponta Pennycook (1994), tem raiz ideológica e não pode ser considerada um processo natural, neutro e inquestionavelmente benéfico para todos os povos sem exceção. $\mathrm{O}$ inglês pode atuar, conforme argumenta o autor, como uma barreira que impede o progresso social e econômico para aqueles que não dominam as variantes de prestígio dessa língua. Dessa forma, é de se esperar que a oferta e procura pelo ensino e aprendizado de outras variantes do inglês, como a jamaicana, a nigeriana e a indiana, por exemplo, sejam praticamente nulas. Conforme aponta García (2015), o objetivo do aprendizado de uma língua adicional sempre foi o de atingir o padrão do "falante nativo", costumeiramente entendido como o falante branco, de classe média, que tem um certo nível de instrução acadêmica. A ideologia da existência de um "falante nativo" monolítico, portanto, não reconhece o "nativismo" de outras práticas linguísticas comuns entre outras classes sociais e outras raças, criando uma ordem de indexicalidade (BLOMMAERT, 2010) que favorece as práticas linguísticas dos mais poderosos. Blommaert também relata que o preconceito linguístico em relação às variantes menos prestigiosas do inglês chega a levar alguns de seus falantes a fazer cursos que lhes ensinam a assimilar o sotaque do outro ${ }^{1}$.

Em busca de inserção no mercado globalizado, no Brasil, procuramos aprender a língua inglesa prestigiosa. Deparamo-nos com inúmeras ofertas de cursos de inglês que dispõem de professores "nativos" como uma grande vantagem e até mesmo garantia de um aprendizado melhor, como se o inglês do "nativo" fosse o modelo "autêntico" da língua uma vez que é livre de marcas locais e de mesclas com outras línguas. $O$ inglês "nativo" representaria um inglês puro e verdadeiro. A mesma preocupação em oferecer tais modelos de inglês é demonstrada por muitos livros didáticos que mencionam seguir a variante americana ou britânica (a menção pode vir até mesmo no título) ${ }^{2}$ e oferecem insumo linguístico que segue somente os padrões dessas variantes. As cores das bandeiras da Grã-Bretanha e dos Estados Unidos estão frequentemente presentes nas capas dos livros e nos logos dos cursos de inglês.

Essa tradição de ensino e aprendizado de inglês que seguimos não considera que o inglês, hoje, pertence muito mais a falantes não-nativos do que nativos (CRYSTAL, 2004) e que os falantes de inglês brasileiros são bilíngues que se enunciam a partir de suas culturas brasileiras locais. Ainda perdura uma visão de língua direcionada pelo que Canagarajah (2013) chama de "paradigma monolíngue", constituído, fundamentalmente, com base em pressupostos de que existiria equivalência entre língua, comunidade e território, uma língua equivaleria a uma única identidade nacional e que as línguas seriam sistemas independentes e existiriam como entidades puras e separadas umas das outras. A partir desses pressupostos, derivam outros, segundo os quais uma língua seria um sistema construído pela cognição e não pelo contexto social, a

\footnotetext{
${ }^{1}$ Blommaert (2010, p. 22) aponta que, apesar de as pessoas aprenderem inglês nas escolas na Índia e de essa variante ser perfeitamente adequada para a maior parte de suas negociações comunicativas, elas precisam recorrer a cursos privados que ensinam o sotaque americano se quiserem trabalhar na indústria próspera dos call centers.

2 Ver, por exemplo, o site da editora Macmillan: <http://www.macmillan.com.br/catalogo/indice-porcolecao/pg/4/>.
} 
comunicação estaria centrada na gramática e não na prática comunicativa e a forma seria isolada de sua inserção ecológica.

Frente ao que foi discutido até aqui, o objetivo deste artigo é o de problematizar a nossa tradição de ensino de língua inglesa, que trata qualquer marca local de uso do inglês e a possibilidade de transitar entre línguas como deficiência e evidência de alienação (CANAGARAJAH, 2013, p. 12). O corpus deste trabalho foi obtido a partir de uma pesquisa maior de mestrado ${ }^{3}$, por meio de observações de aulas de inglês para adolescentes brasileiros no ano de 2012, em aulas particulares e em uma escola bilíngue de Ensino Fundamental.

Proponho uma análise interpretativista de excertos selecionados das observações de aula, apoiada em teorias que auxiliam na compreensão da ligação entre língua e cultura (HALL, 1997; CUCHE, 2002; AGAR, 1994) e do bilíngue e suas práticas discursivas (MAHER, 2007; MELLO, 1999; ROMAINE, 1995; GARCÍA, 2009; BUSCH, 2010; 2012; CANAGARAJAH, 2013) com o objetivo de apontar para o fato de que há duas representações equivocadas acerca do processo de ensino e aprendizagem de inglês, a saber: (i) misturar as línguas é sinal de incompetência e (ii) marcas locais de uso do inglês sinalizam falhas no processo de ensino e aprendizado da língua ${ }^{4}$.

Para explicar por que tais representações são equivocadas, analiso alguns excertos de falas bilíngues a partir de uma visão heteroglóssica de língua. Para apoiar minha análise, primeiramente, discorro sobre a relação intrínseca entre língua e cultura. Em seguida, discuto as noções de bilíngue e suas práticas discursivas. $\mathrm{Na}$ seção seguinte, descrevo a metodologia utilizada neste trabalho e, depois, apresento a análise e a discussão dos registros. Por fim, teço algumas considerações finais.

\section{Língua e cultura: uma relação de interdependência}

Entre os diversos significados agregados à palavra "cultura" desde a Idade Média (cultivo da terra, formação e educação formais e trabalhos artísticos e literários, por exemplo), interessa-nos, para este trabalho, a noção que remete, em sentido mais amplo, aos modos de agir e pensar de um povo. Conforme relata Cuche (2002, p. 11), "nada é natural no homem. Mesmo as funções humanas que correspondem às necessidades fisiológicas, como a fome, o sono, o desejo sexual etc., são informados pela cultura". Podemos concluir, portanto, que também é a cultura, e não somente a biologia, que nos molda e determina como interagimos com o mundo.

É nesse sentido que podemos entender a cultura como um "sistema compartilhado de valores, de representações e de ações, que orienta a forma como vemos e damos inteligibilidade às coisas que nos cercam" (MAHER, 2007, p. 261). A maneira como esse sistema é compartilhado pode ser esclarecida pelo conceito de

\footnotetext{
3 CAMARGO, H. Duas línguas e uma cultura: Traços de brasilidade evidenciados em falas de professoras e de adolescentes bilíngues em português e inglês. 2014. 90 f. Dissertação (Mestrado em Linguística Aplicada) - Instituto de Estudos da Linguagem da Universidade Estadual de Campinas, Campinas, 2014.

${ }^{4}$ Refiro-me às marcas locais como toda e qualquer manifestação cultural da comunidade onde a Língua Inglesa é adquirida. Exemplos de marcas locais serão explicitados na seção de análise e discussão dos registros apresentados neste trabalho.
} 
representação proposto por Hall (1997), que considera a linguagem como algo público e social e entende que o significado de tudo o que existe no mundo é fruto de sentido coletivo, construído por meio do uso de sistemas representacionais. Ou seja, nada possui um significado prévio, pronto para ser compreendido e nomeado, tampouco as pessoas individualmente podem atribuir sentido às coisas e nomeá-las, uma vez que todo e qualquer sentido é construído coletivamente por meio das ações sociais usando conceitos e signos.

São dois os sistemas representacionais propostos por Hall (1997, p. 17): o sistema de representação propriamente dito e a linguagem. $O$ primeiro determina que "todos os tipos de objetos, pessoas e eventos sejam correlacionados com um conjunto de conceitos ou representações mentais que carregamos em nossas mentes". É esse sistema que nos permite interpretar o mundo significativamente, uma vez que o significado depende do sistema de conceitos e imagens formados em nossas mentes, que nos permite relacionar o mundo mental com o real. Claro que a maneira como compreendemos e interpretamos o mundo não é exatamente igual para todos os indivíduos de uma comunidade, mas é parecida o suficiente para que consigamos compartilhar nossos pensamentos e expressar nossas ideias, pois partilhamos os mesmos mapas conceituais. É nesse sentido que Hall (1997) acredita ser possível dizer que pertencemos a uma cultura.

O segundo sistema representacional, a linguagem, é o meio pelo qual expressamos a forma como interpretamos o mundo em forma de escrita, fala e imagens. É a linguagem que nos possibilita construir um conjunto de correspondências entre nosso mapa conceitual e um conjunto de signos reunidos ou organizados em linguagens que representam os conceitos. Os dois sistemas relacionados engrenam o processo de criação de sentido na cultura e revelam a existência de uma relação de interdependência entre linguagem e cultura, pois ao mesmo tempo em que a linguagem tem a função de transmitir a cultura, ela mesma é marcada pela cultura (CUCHE, 2002, p. 94). O termo linguacultura cunhado por Agar (1994) ilustra bem a relação intrínseca entre língua e cultura.

Portanto, é natural que nos enunciemos culturalmente brasileiros mesmo quando falamos inglês. Marcas locais que caracterizam a forma como interagimos socialmente são inevitáveis e não deveriam ser classificadas como erros, como, por exemplo, quando um aluno chama sua professora de teacher ou alguém termina cartas pessoais com kisses. O que se nota nesses casos não é falta de conhecimento linguístico, mas que os interagentes continuam sendo brasileiros em inglês, principalmente quando consideramos o contexto de ensino e aprendizado dessa língua no Brasil, no qual os interagentes partilham a mesma cultura, falam português e não necessitam do inglês para a comunicação entre si.

Utilizar uma língua envolve mais do que simplesmente apropriar-se de sua gramática e de seu léxico (haja vista a deficiência de ferramentas de tradução), pois o sentido é sempre construído a partir das representações atreladas à linguagem por determinada comunidade e das especificidades dos contextos enunciativos. Assim, é inevitável que o inglês, aprendido como língua estrangeira, no contexto brasileiro receba insumo "linguacultural" do português. E esse inglês nosso não poderia jamais

\footnotetext{
${ }^{5}$ Ver Agar (1994).
} 
equivaler ao americano, britânico, canadense ou qualquer outro. Ele seria a variante "inglês brasileiro".

\section{Compreendendo o bilíngue e suas práticas discursivas}

Apesar de equivocada, a definição do bilíngue como alguém capaz de falar duas línguas perfeitamente ainda habita o imaginário de muitas pessoas. Isso se deve em grande parte à contribuição de alguns dos primeiros autores a versar sobre o tema, como Bloomfield (1933), Haugen (1953) e Thiery (1978), que, embasados em uma perspectiva monoglóssica de língua, defenderam a ideia de um bilíngue balanceado incumbido de utilizar suas duas línguas da mesma maneira que faria um falante nativo de cada uma delas. Aos olhos desses autores, é como se o bilíngue fosse perfeitamente capaz de separar as línguas de seu repertório para expressar-se com igual destreza, cada hora em uma delas.

No entanto, desde a emergência dos estudos da sociolinguística em 1960, ou seja, das questões relacionadas a como as línguas e seus usos variam de acordo com o contexto social e com os interlocutores envolvidos, o sujeito bilíngue é hoje entendido para muito além da tradicional concepção de bilinguismo balanceado (GARCÍA, 2009, p. 45). Colaborando com a desconstrução da concepção de bilinguismo balanceado, Romaine (1995) e Maher (2007) constatam que os bilíngues raramente são igualmente fluentes nas duas línguas em todos os domínios possíveis, pois seu nível de competência nelas pode variar de acordo com o tópico, a modalidade, o gênero discursivo em questão, as necessidades impostas por sua história pessoal e as exigências de sua comunidade linguística. Além disso, García (2009) destaca que nem sempre as duas línguas de um indivíduo têm o mesmo poder ou prestígio social, levando-o a utilizá-las de maneiras diferentes de acordo com os propósitos e contextos comunicativos bem como as pessoas envolvidas nas interações.

Além de desconsiderar a existência de um sujeito bilíngue balanceado, García (2009) ainda questiona os modelos de bilinguismo monoglóssicos que nomeiam uma língua como a primeira e a língua adicional como a segunda, mantendo a noção de língua como uma entidade estática, autônoma e abstrata, regida por um conjunto finito de regras gramaticais e por itens lexicais relativamente estáveis. Percebemos, portanto, que os modelos de bilinguismo monoglóssicos focalizam a língua em si e consideram apenas o uso que o falante faz de cada uma de suas línguas sem atentar para os modos como ele transita entre elas para construir sentidos em seus contextos bilíngues. Dada a grande complexidade linguística do século XXI, impulsionada pela grande mobilidade geográfica, física ou virtual, que a globalização e as novas tecnologias incentivam, esses modelos monoglóssicos não parecem corresponder às práticas reais dos bilíngues. Dessa forma, faz-se necessário pensar o bilinguismo de uma maneira em que o indivíduo bilíngue, e não o uso que ele faz de suas línguas, esteja no centro das análises de práticas linguísticas. Para tanto, García (2009) propõe que as noções de indivíduo bilíngue e, consequentemente, de bilinguismo sejam reconsideradas a partir de uma visão heteroglóssica de língua, ou seja, uma visão que considera as línguas como entidades cambiáveis, permeáveis e multimodais e os bilíngues como indivíduos constituídos na imbricação de suas línguas.

Nessa perspectiva, ao examinar as práticas linguísticas de indivíduos bilíngues, García (2009) define que tais práticas são exemplos de translinguismo. Para a autora, a 
noção de translinguismo refere-se às múltiplas práticas discursivas nas quais os bilíngues se engajam e que dão sentido aos seus mundos. Segundo a autora, o translinguismo "reflete mais variações e mais escolhas de expressão do que as dispostas a cada monolíngue separadamente e transmite não só conhecimento linguístico como também cultural que afeta o uso da língua" (GARCÍA, 2009, p. 47). Portanto, o conceito de translinguismo implica uma orientação mais dinâmica dos sistemas linguísticos, pois sustenta que os códigos podem fundir-se para criar significados relevantes e novas indexicalidades.

Canagarajah (2013) contribui com a noção de "práticas translíngues", segundo as quais as línguas de um indivíduo não são mantidas em compartimentos cognitivos separados, cada qual com seu tipo de competência e sua associação a diferentes grupos linguísticos. Segundo o autor, as línguas podem até mesmo integrar-se aos recursos semióticos do repertório ou da sociedade de um indivíduo, interagindo e formando parte de um recurso integrado que amplia os sentidos tanto dos recursos linguísticos como os dos semióticos. Assim, o autor explica que, para um indivíduo bilíngue, suas línguas fazem parte de um repertório que é acessado para propósitos comunicativos.

Busch (2012) também defende a noção de repertório linguístico em detrimento das divisões clássicas de primeira e segunda língua. Para tanto, a autora propôs uma redefinição do conceito de repertório verbal de uma comunidade de fala de Gumperz (1960, 1964) a partir da condição de superdiversidade (VERTOVEC, 2007). Para Gumperz (1964, p. 137), o repertório verbal de uma comunidade de fala é definido como "a totalidade das formas linguísticas empregadas no curso das interações socialmente significativas".

A ideia de comunidade de fala, proposta por Gumperz (1968, p. 219), como um "grupo humano caracterizado por manter interações frequentes e regulares por meio de um conjunto de signos verbais compartilhados" é redimensionada por Vertovec (2007), que invoca o conceito de superdiversidade. $\mathrm{O}$ autor tem como objetivo enfatizar o fato de que houve um crescimento enorme nas categorias de imigração. Isso ocorreu não apenas em termos de nacionalidade, etnicidade, língua e religião, mas também em decorrência das diferentes razões para a imigração e dos diferentes padrões e itinerários dos contingentes migratórios. A noção de superdiversidade sugere que a comunidade de fala proposta por Gumperz (1968) já não é mais tão facilmente caracterizada.

Frente ao que vem sendo discutido, podemos questionar conceitos com que operamos no ensino e aprendizado da língua inglesa no Brasil, como "língua estrangeira", "língua materna" e "aprendizes de segunda língua", bem como as metodologias que impõem o uso de uma única língua na sala de aula por parte dos professores - principalmente - e dos alunos. Se passarmos a entender o bilinguismo a partir da perspectiva dos próprios bilíngues, que "translinguam" como uma prática comum, poderemos substituir o termo "aprendizes de língua estrangeira" simplesmente por "indivíduos bilíngues", ou seja, indivíduos que utilizam os recursos linguísticos e semióticos de seus repertórios para construir sentidos em seus contextos bilíngues. Essa mudança de perspectiva poderia resultar em uma mudança na prática do ensino e aprendizado de inglês, pois, de acordo com ela, a mistura entre línguas e marcas locais de uso do inglês são vistas simplesmente como características do bilíngue e jamais como sinais de incompetência e falha no processo de ensino e aprendizado da língua inglesa. 


\section{Metodologia}

Os registros apresentados neste trabalho foram retirados de uma pesquisa maior que baseou a dissertação de mestrado de Camargo (2014). Para gerar os registros, observei aulas de inglês para adolescentes entre 13 e 16 anos em dois contextos diferentes: em aulas particulares de inglês ministradas por mim e em uma escola bilíngue de Ensino Fundamental II na cidade de São Paulo no ano de 2012.

Além dos adolescentes, com idades entre 13 e 16 anos, paulistanos e de classe alta, os participantes da pesquisa também foram duas professoras, com idades entre $32 \mathrm{e}$ 40 anos, uma delas paulistana e a outra carioca. Os adolescentes da escola bilíngue, na época das observações, cursavam os $8^{\circ}$ e $9^{\circ}$ anos do Ensino Fundamental II, e as jovens das aulas particulares cursavam o $2^{\circ}$ ano do Ensino Médio em uma escola particular. É importante ressaltar que os adolescentes participantes da pesquisa iniciaram seu processo de aprendizado da língua inglesa ainda na infância e, portanto, encontravam-se em um estágio de aquisição linguística avançado. Para preservar sua privacidade, todos os participantes estão identificados com nomes fictícios.

Os registros gerados para a pesquisa referem-se a produções orais em inglês realizadas espontaneamente por adolescentes e por suas professoras. No viés da pesquisa qualitativa, é importante levar em conta o contexto no qual os enunciados ocorrem para que se possa entendê-los e analisá-los. A noção de contexto a que me refiro aqui engloba tanto os aspectos discursivos como os de interação local (FLICK, 2009, p. 298). Dessa forma, para analisar os registros, é importante observar situações em que os participantes possam falar espontaneamente, permitindo, assim, uma produção de material textual suficiente para ilustrar o contexto, segundo o qual o pesquisador deve proceder sua análise (FLICK, 2009, p. 44). As convenções adotadas para a transcrição dos registros são baseadas na seguinte proposta:

\begin{tabular}{|c|c|}
\hline CONVENÇÕES & UTILIZADAS NAS TRANSCRIÇÕES DE REGISTROS ORAIS \\
\hline , & Pausa de menos de 02 segundos \\
\hline$?$ & entonação indicando pergunta \\
\hline$!$ & entonação indicando exclamação \\
\hline MAIÚSCULAS & entonação enfática \\
\hline :: & alongamento de vogal \\
\hline ... & pausa de mais de 02 segundos \\
\hline$(\ldots)$ & supressão de trecho da fala \\
\hline$((\mathbf{I N C}))$ & trecho incompreensível \\
\hline (piso) & transcrição duvidosa \\
\hline I & marca de corte sintático abrupto \\
\hline [ & Fala simultânea ou sobreposta \\
\hline ((sorrindo)) & Descrição de atividade não vocal \\
\hline eh, ah, hum, ahã & Pausa preenchida, \\
\hline
\end{tabular}

Baseado em proposta de Marcuschi (1999) 
Para o recorte apresentado neste trabalho, foram selecionados alguns registros de modo a ilustrar como os participantes bilíngues acessam seus repertórios linguísticos para construir sentido. A seguir, apresento a análise e discussão dos registros. 


\section{Análise e discussão dos registros}

A partir dos registros gerados durante as observações de aula na escola bilíngue e nas aulas particulares, delimitei excertos que considero relevantes para mostrar quão equivocadas são as representações que consideram (i) a mistura entre línguas um sinal de incompetência e (ii) as marcas locais de uso do inglês um sinal de falhas no processo de ensino e aprendizado da língua.

Os dois primeiros excertos selecionados apontam para a relação intrínseca entre língua e cultura e também para o caráter multimodal da língua. Ambos excertos foram gerados durante uma aula particular para duas jovens de 16 anos, Paloma e Gabi, na qual a questão do humor seria tematizada por meio de um vídeo de um sketch dos Muppets, um programa de televisão americano muito famoso nas décadas de 70 e 80 . Nesse sketch, os personagens faziam trocadilhos com palavras relacionadas à vaca. Como tentativa de garantir o entendimento do humor contido nesses trocadilhos, foi preparada uma atividade com o intuito de previamente ensinar o vocabulário e expressões que apareceriam no sketch, como, por exemplo, "heard" (verbo ouvir no passado) e "herd" (rebanho); "steak" (bife) e "stake" (risco). A atividade consistia em mostrar algumas imagens de modo a, explorando os campos semânticos associados ao animal, verificar se as alunas conseguiam nomeá-las em inglês (caso contrário, a palavra deveria ser ensinada). As imagens mostradas foram a de uma vaca, de um homem ordenhando esse animal, de um par de chifres, de um bife e de um rebanho. Vejamos, a seguir, o primeiro trecho da interação ocorrida durante essa atividade.

(1) PROFESSORA: we're gonna talk about ah... puns... today

PALOMA: [ok

GABI: [ok

PROFESSORA: and in order for you to understand a little sketch I need to teach you some words some vocabulary,

PALOMA: ok

PROFESSORA: related to COW s... so what comes to your mind when you think of cows?

PALOMA: ((em tom hesitante)) can I say... ANYthing?

PROFESSORA: sure!

PALOMA: PU::tas ((todas riem))

PROFESSORA: may::be ((risos))... in english if you, if you call a woman a cow you're not calling her a promiscuous woman, maybe fat...ok?...

A associação feita por Paloma revela como o seu mapa conceitual, que lhe é conferido por sua cultura brasileira e que se manifesta no uso que ela faz da linguagem, entra em ação na hora de construir sentidos também em língua inglesa. A participante atribui ao termo "cow" (que em inglês se refere ao animal "vaca") a conotação típica da língua portuguesa de "vaca" para se referir a uma "prostituta" ou "puta", termo esse cujo sentido, hoje em dia, se estende às mulheres consideradas promíscuas, "fáceis" e até mesmo às meninas que flertam e "ficam" com meninos ainda que eles sejam comprometidos. Essa associação revela também o caráter machista da cultura brasileira, de acordo com a qual o comportamento de mulheres que respondem aos seus desejos e interesses sexuais é visto como desviante.

Além disso, podemos observar que o translinguismo (a interação estava ocorrendo em inglês) realizado por Paloma quando ela diz "PU:tas" só é possível porque os participantes dessa interação compartilham a mesma língua e o mesmo mapa conceitual, o que faz com que interpretem o mundo de maneira semelhante (AGAR, 
1994, 2006). É por estar em interação com membros de sua cultura brasileira e bilíngues em português e inglês como ela que Paloma pôde escolher trocar a língua em uso para expressar uma representação de "vacas" possível de ser construída no interior de sua cultura. O fato de a professora e Gabi rirem junto com Paloma quando ela diz "PU::tas" é indicativo de que a cultura e as línguas em questão são, de fato, compartilhadas. Caso houvesse algum estrangeiro não proficiente em português presente na interação, Paloma teria precisado decidir se negociaria, ou não, sua linguacultura com a linguacultura desse outro optando entre fazer ou não a associação que fez ou explicá-la utilizando, para tanto, termos em inglês. Podemos notar, portanto, a versatilidade inerente ao contexto bilíngue, em que explicações podem ser poupadas e mais sentidos podem ser construídos graças ao repertório linguístico disponível.

O próximo excerto refere-se à interação que ocorreu no momento em que a professora mostrou a imagem de um par de chifres às alunas, que logo a relacionaram ao ato de um marido trair sua esposa, conotação perfeitamente aceita no Brasil.

(2) PROFESSORA: do you know how to say this in english?

GABI: hum... horns

PROFESSORA: go::od!

GABI: ((rindo)) it's like when the:: husband jumps the wall

PALOMA: hum... wall, no::, it's that [thing that...

GABI:

[it's like made with... [metal but I don't know...

PALOMA:

[yes!

PROFESSORA: fence?

PALOMA: YE::S

PROFESSORA: ((rindo)) when the husband jumps the fence?

PALOMA: ((rindo)) [ye::ah

GABI: ((rindo)) [ye::ah

PROFESSORA: I, I'm not sure w::e have that idiom in english...

GABI: ok, how can you say it?.[she's

PROFESSORA: $\quad[$ she's, yeah... he's CHEAting on her...

Após a professora perguntar se as alunas sabiam qual era a palavra em inglês que correspondia à imagem dos chifres, Gabi tomou a iniciativa e disse a palavra em inglês corretamente (hum... horns), mas não conseguiu evitar a associação entre chifres e "ser chifrado", o que equivale a ser traído em um relacionamento romântico. Gabi expressa uma conotação construída em sua cultura brasileira, a de pular a cerca como equivalente a trair, em inglês (when the husband jumps the fence). Apesar de a associação em si não ser evidência do machismo presente na cultura brasileira, o fato de Gabi referir-se especificamente ao marido que pula a cerca, e não à esposa ou simplesmente à pessoa, mostra que ela está inserida em uma cultura machista, em que o homem é quem tem o direito ao desejo sexual buscando atendê-lo também fora do casamento. Apesar de ambos os gêneros poderem "levar um chifre", Gabi confere ao homem a posição de traidor, e a professora faz o mesmo.

Nesse excerto, também se percebe o caráter multimodal das línguas relatado tanto por Hall (1997) ${ }^{6}$ como por Canagarajah (2013). De fato, as alunas constroem um

\footnotetext{
6 Hall (1997, p. 18-19) considera que a definição de língua deve ser estendida para além dos sistemas escritos e falados para compreender todos os signos capazes de produzir sentido, como imagens visuais
} 
sentido para a imagem de um par de chifres que lhes foi mostrada. Entretanto, embora elas tenham nomeado a imagem corretamente em inglês, o sentido construído para "horns" é uma possibilidade na cultura brasileira e não na de algum "falante nativo". Nesse sentido, percebemos que, para elas, não importa a língua sendo utilizada, sua representação sobre chifres não muda: o significante pode mudar, mas o significado não.

Uma observação relevante acerca desses dois excertos é que as falantes alteram o sentido de "cow" e de "horns" para que essas palavras passem a significar "putas" (em seu sentido estendido) e "traição". Assim, o próprio sentido de "cow" pode passar a ter uma nova conotação, e o mesmo ocorre com "horns". Essa alteração de sentido referese ao que Halliday (2002 apud CANAGARAJAH, 2013) denominou semiodiversidade em oposição ao termo glossodiversidade, que engloba o surgimento de novas formas e variantes do inglês. Em seu capítulo sobre o inglês como translíngue, Canagarajah (2013, p. 57) aponta que a semiodiversidade pode ocorrer mesmo sem haver mudanças na forma, uma vez que "a mesma palavra ou o mesmo item gramatical pode ser utilizado para indicar novos valores e sentidos conforme eles viajam por contextos espaço-temporais diversos". O conceito de translinguismo, portanto, ajuda-nos a entender que novos sentidos emergem de práticas semióticas. Portanto, não devemos tomar os padrões e sistemas de formas pré-estabelecidas tidas como estáveis e originais como base para a construção de sentidos, pois eles também estão constantemente passando por mudanças, uma vez que também são construídos nas práticas comunicativas.

O excerto que segue corresponde à transcrição de um trecho de interação ocorrida no $9^{\circ}$ ano da escola bilíngue observada. Durante a discussão de um texto do livro didático adotado para essa turma, os alunos notaram que esse livro correspondia a uma série escolar inferior à sua e questionaram a professora quanto a isso. A professora concordou que o livro de fato não estava adequado e explicou que a atual coordenadora, responsável pela seleção de material didático, não havia feito tal escolha. Os alunos, então, começaram uma discussão sobre quem poderia ter escolhido o livro.

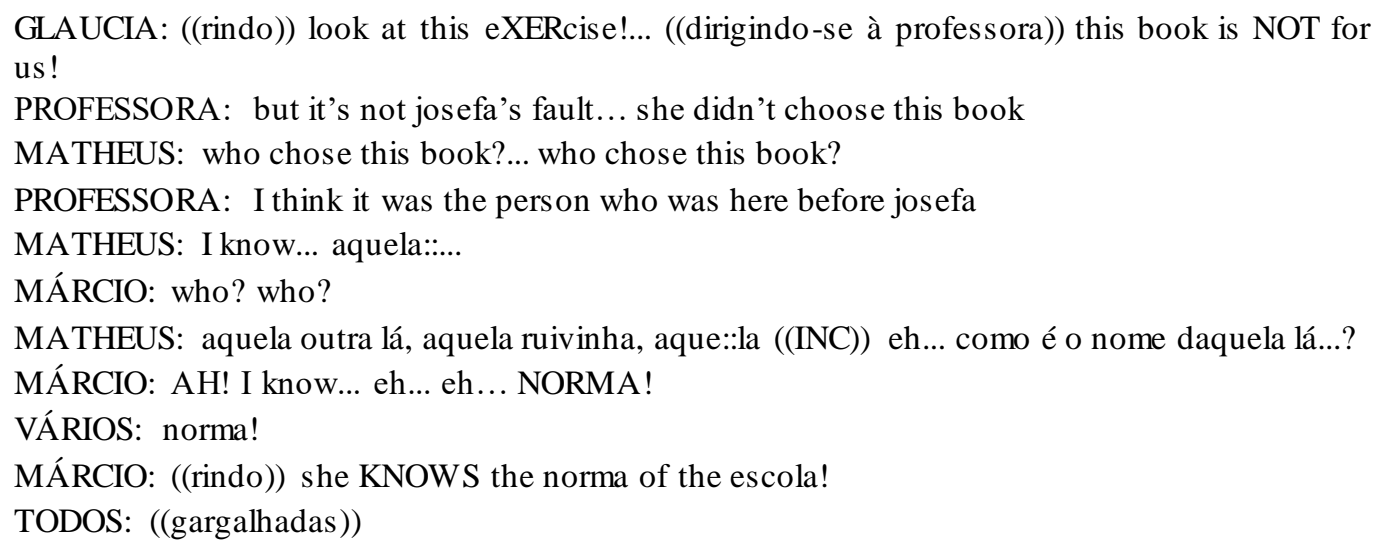

Nesse excerto, podemos observar uma construção de sentido envolvendo rima, ironia e humor que só pode ser realizada e compreendida em um contexto bilíngue. Quando Márcio consegue, por fim, lembrar-se do nome da profissional que adotara o 
livro para sua turma - Norma - ele faz um trocadilho para indicar que ela não agira de acordo com as orientações da instituição por meio da alteração entre inglês e português ("she KNOWS the norma of the escola!"). Podemos notar a ironia utilizada pelo jovem em seu tom acentuado em "knows", dizendo que ela conhece as normas da escola para, na verdade, indicar que ela não as conhece. Além de o tom humorístico e irônico do trocadilho dissolver a tensão gerada por um assunto tão sério - algo característico da cultura brasileira - quanto a subestimação da turma, podemos notar o modo criativo com que Márcio utiliza seu repertório linguístico. O trocadilho entre Norma, nome próprio, e norma, substantivo comum sinônimo de "regra", só faz sentido em português. Embora Norma também seja um nome próprio em inglês, ele não equivale ao substantivo "norm" (norma/regra). A palavra "school", equivalente a "escola" em inglês, não rimaria nem com Norma nem com "norm", daí a escolha de Márcio por alternar novamente para o português e utilizar o termo "escola". É importante frisar que a compreensão da construção de sentido desse trocadilho só é possível em uma interação entre bilíngues e que o reconhecimento da criatividade e competência linguística de Márcio são provenientes de uma visão heteroglóssica de língua. De acordo com a perspectiva monoglóssica de língua, Márcio possivelmente seria considerado semilíngue, ou seja, alguém que não domina nenhuma de suas línguas.

Outro ponto interessante observado nessa interação é o caráter cordial da cultura brasileira, que aproxima as pessoas ignorando graus de hierarquia, conforme notamos na maneira como a professora refere-se à coordenadora apenas pelo seu primeiro nome (Josefa). É muito provável que, em um tipo de contexto ou de interação envolvendo "falantes nativos", a professora fizesse uso de um axiônimo seguido do sobrenome de Josefa (Ms., Mrs. ou Miss Silva, por exemplo). Em contexto brasileiro e em interação com outros brasileiros, é perfeitamente aceitável para a professora referir-se a seu superior na escala hierárquica da escola pelo primeiro nome. Portanto, a falta de axiônimos não poderia ser considerada uma alienação linguística, pois representa uma marca cultural.

\section{Considerações finais}

Apesar de nossa prática de ensino e aprendizado de inglês estar baseada em uma visão monoglóssica de língua, podemos concluir, com base nas análises e discussões dos registros apresentados neste trabalho, que o resultado dessa prática, ou seja, a utilização real da língua inglesa como meio de comunicação e expressão, reflete um comportamento linguístico heteroglóssico. Por disporem de um repertório linguístico constituído de duas línguas (português e inglês), os falantes recorrem às diversas possibilidades disponíveis a eles para construir sentido de seus universos bilíngues. Como fazem parte e compartilham de uma mesma cultura brasileira, os falantes constroem suas representações de tudo o que existe no mundo baseados nessa cultura, expressando-as por meio de suas línguas. Isso quer dizer que, tanto em português como em inglês, os falantes interagem segundo as normas interacionais de sua cultura brasileira.

Centralizar nossas análises nas práticas linguísticas de indivíduos bilíngues, em vez do uso que o falante faz de cada uma de suas línguas, pode nos auxiliar a desenvolver práticas de ensino e aprendizado de inglês, e de outras línguas adicionais, que atendam melhor às necessidades linguísticas dos falantes. A noção de 
translinguismo, abarcada por esse deslocamento de foco, proporciona um entendimento melhor da fluidez e da criatividade das práticas bilíngues, colocando por terra a visão de que a mistura entre línguas seja um sinal de incompetência. Além disso, a noção de translinguismo pode nos permitir ensinar e aprender inglês levando em consideração o respeito por nossa cultura brasileira e, dessa forma, deixar de considerar marcas locais de uso do inglês como falhas no processo de ensino e aprendizado.

Dada a complexidade dos contextos atuais de contato com a língua inglesa, mais importante do que voltar nossa atenção para a descrição de formas ou variantes linguísticas é focalizar as construções de sentidos desenvolvidas nas práticas comunicativas que envolvem essa língua. Já que é a prática que gera sentido, as formas mais incomuns e até mesmo violações de sistemas e normas pré-estabelecidos podem contribuir para a criação de novos sentidos. Não quero dizer que o foco nas questões de forma da língua inglesa padrão não deva ser valorizado, pois precisamos compartilhar essa língua com outras comunidades de maneira inteligível e, portanto, necessitamos de um acordo quanto ao que deve ser ensinado. No entanto, para atender às necessidades comunicativas do século XXI, é necessário que se reconheçam as novas significações construídas na imbricação das línguas e das diferentes culturas dos falantes tanto como produto do aprendizado quanto do desenvolvimento linguístico.

Ao contrário das representações sobre mistura entre línguas e marcas locais de uso construídos com base em uma visão monoglóssica de língua, os excertos evidenciam a competência e a criatividade dos participantes no uso de seu repertório linguístico, haja vista sua capacidade de utilizar suas línguas eficientemente para comunicar o que desejam, seja humor, seja uma conotação, seja uma rima. Indivíduos linguisticamente incompetentes não seriam capazes de comunicar e expressar tanto. No entanto, é necessário que adotemos uma visão heteroglóssica de língua em nossa prática de ensino e aprendizado de língua inglesa para podermos reconhecer e apreciar as construções bilíngues.

\section{REFERÊNCIAS}

AGAR, M. Language shock: understanding the culture of conversation. Nova York: William Morrow, 1994. 284 p.

BLOMMAERT, J. The Sociolinguistics of Globalization. Cambridge: Cambridge University Press, 2010. 213 p.

BLOOMFIELD, L. Linguistic aspects of science. Philosophy of Science 2: 499-517. Reprinted in Hockett, 1970, p. 307-321, 1935.

BUSCH, B. The Linguistic Repertoire Revisited. Applied Linguistics Advance Access, Oxford, p. 1-22, out. 2012.

CAMARGO, H. Duas línguas e uma cultura: Traços de brasilidade evidenciados em falas de professoras e de adolescentes bilíngues em português e inglês. 2014. 90 f. Dissertação (Mestrado em Linguística Aplicada) - Instituto de Estudos da Linguagem da Universidade Estadual de Campinas, Campinas.

CANAGARAJAH, S. Translingual Practice. Global Englishes and Cosmopolitan Relations. Londres e Nova Iorque: Taylor \& Francis Group, 2013. 216 p. 
CRYSTAL, D. A revolução da linguagem. Tradução de Ricardo Quintana. Rio de Janeiro: Jorge Zahar Editora, 2004. 151 p.

CUCHE, D. A noção de cultura nas ciências sociais. Tradução de Viviane Ribeiro. 2. ed. Bauru: EDUSC, 2002. 255 p.

FLICK, U. An introduction to qualitative research. SAGE Publications Limited, 2009. $504 \mathrm{p}$.

GARCÍA, O. Bilingual Education in the 21st century. A global perspective. Malden: Wiley-Blackwell, 2009. $481 \mathrm{p}$.

Misconstructions in the education of language minoritized students. In: ROCHA, C. H.; MACIEL, R. F. (orgs). Língua estrangeira e formação cidadã: por entre discursos e práticas. Pontes Editores, 2015. p. 217-230.

GUMPERZ, J. J. Formal and informal standards in Hindi regional language area. In: FERGUSON, C. A.; GUMPERZ, J. J. (ed.). In: Linguistic Diversity in South Asia. International Journal of American Linguistics, v. 3, p. 92-118, 1960.

Linguistic and social interaction in two communities. In: GUMPERZ, J. J.; HYMES, D. (ed.). The Ethnography of Communication. American Anthropologist, v.66, no. 6, part 2, 1964.

The speech community. In: SILLS, D. L.; MERTON, R. K. (ed.). International encyclopedia of the social sciences. London: MacMillan, 1968. p. 381-386.

HALL, S. The work of representation. In: HALL, S. (Org.). Representation. Cultural representation and cultural signifying practices. London/Thousand Oaks/New Delhi: Sage/Open University, 1997. 391 p.

HAUGEN, E. The Norwegian language in America: a study in bilingual behavior. Philadelphia: University of Pennsylvania Press, 1953. 699 p.

LACOSTE, Y.; RAJAGOPALAN, K. (Orgs.). A geopolítica do inglês. São Paulo: Parábola Editorial, 2005. 159 p.

MACNAMARA, J. Bilingualism in the modern world. Journal of social issues, v. 23, n. 2, p. 1-7, abr. 1967.

MAHER, T. M. Do casulo ao movimento: a suspensão das certezas na educação bilíngüe e intercultural. In: CAVALCANTI, M. C.; BORTONI-RICARDO, S. M. (orgs.). Transculturalidade, linguagem e educação. Campinas: Mercado de Letras, 2007. p. 67-94.

MARCUSCHI, L. A. Análise da Conversação. 5. ed. São Paulo: Ática, 1999. 96 p.

MELLO, H. A. B. O Falar Bilíngue. Goiânia: Editora UFG, 1999. 178 p.

PENNYCOOK, A. The cultural politics of English as an international language. New York: Longman Group Limited, 1994.

ROMAINE, S. Bilingualism. 2. ed. Nova York: Basil Blackwell, 1995. 384 p. 
THIERY, C. True bilingualism and second language learning. In: GERVER, D.; SINAIKO, H. W. (eds.). Language, interpretation and communication. Nova York: Plenum, 1978. p. 145-146.

VERTOVEC, S. Super-diversity and its implications. Ethnic and Racial Studies, v.30, n.6, p. 1024-1054, nov. 2007.

Recebido em: 11/09/2015

Aprovado em: 11/06/2016 